\title{
Time-dependent and dose-dependent effects of fenfluramine upon pain thresholds
}

\author{
RICHARD J. BODNAR and DONALD SIMONE \\ Department of Psychology, Queens College, City University of New York, Flushing, New York 11367 \\ DENNIS D. KELLY, MARTIN BRUTUS, and MURRAY GLUSMAN \\ Department of Behavioral Physiology, New York State Psychiatric Institute
}

New York, New York 10032

and

\author{
RICHARD MEIBACH \\ Department of Pharmacology, Mount Sinai School of Medicine, New York, New York 10029
}

\begin{abstract}
Fenfluramine increases brain serotonin levels soon after injection, followed by chronic serotonin depletions 48-72 $\mathrm{h}$ thereafter. Because serotonin content has been implicated in both basal and analgesic nociceptive processes, the present study evaluated fenfluramine's dose-dependent and time-dependent effects upon pain thresholds in rats as measured by three tests: flinchjump, tail flick, and liminal escape. Fenfluramine increased all three nociceptive thresholds $.5 \mathrm{~h}$ following injection. Important test-specific differences were observed, with antinociceptive responses following effective fenfluramine doses of $2.66 \mathrm{mg} / \mathrm{kg}$ on the flinch-jump test, $13.3 \mathrm{mg} /$ $\mathbf{k g}$ on the tail-flick test, and $26.6 \mathrm{mg} / \mathrm{kg}$ on the liminal escape test, with the last effect apparently due to overall behavioral disruption. In contrast, fenfluramine failed to alter pain thresholds 48 and $72 \mathrm{~h}$ after injection but significantly decreased tail-flick latencies $96 \mathrm{~h}$ following the lowest dose. Previous reports of morphological abnormalities following fenfluramine administration were not confirmed. While these data confirm previous reports that increases in serotonin levels produce antinociceptive effects, they do not support the contention that serotonin depletion results in hyperalgesia.
\end{abstract}

Serotonin is intricately involved in the mediation of an organism's nociceptive responsiveness (see review by Messing \& Lytle, 1977). Increases in pain thresholds and decreases in brain serotonin occur in animals following (1) procedures that produce lesions in the medial forebrain bundle, septum, dorsomedial tegmentum, or nucleus accumbens, (2) systemic parachlorophenylalanine or p-chloroamphetamine injections, and (3) maintenance on tryptophan-poor diets (Gorlitz \& Frey, 1972; Harvey \& Lints, 1971; Lints \& Harvey, 1969; Lorens, Sorenson, \& Harvey, 1970; Lytle, Messing, Fisher, \& Phebus, 1975; Tenen, 1967; Yunger \& Harvey, 1973). Moreover, opiate analgesia is diminished by serotonin-depleting manipulations such as procedures that produce lesions in the dorsal raphe nucleus, the nucleus raphe magnus, or the dorsolateral funiculus of the spinal cord, and injections of either parachlorophenylalanine or 5,6 dihydroxytryptamine (Basbaum, Marley, O'Keefe, \& Clanton, 1977; Proudfit \& Anderson, 1975; Samanin, Ghezzi, Mauron, \& Valzelli, 1973; Tenen, 1968; Vogt, 1974). On the other

This research was supported by NINCDS Grant 14449 and NYS HRC Grant 1518 . The FEN was donated by A. H. Robins Laboratories. Address all correspondence to Richard J. Bodnar, Department of Psychology, Queens College, C.U.N. Y., Flushing, New York 11367. hand, serotonergic uptake inhibition and serotonergic receptor agonism increase pain thresholds (Messing, Fisher, Phebus, \& Lytle, 1976; Samanin, Bernasconi, \& Quattrone, 1976).

However, not all brain serotonin alterations modulate all aspects of pain thresholds. While both lesions placed in midbrain raphe nuclei and 5,7 dihydroxytryptamine injections reduce morphine analgesia, they fail to alter basal pain sensitivity (Blasig, Reinhold, \& Herz, 1973; Harvey, Schlosberg, \& Yunger, 1974; Hole \& Lorens, 1975). Conversely, medial forebrain bundle lesions, which decrease basal pain thresholds, fail to alter opiate analgesia (Harvey et al., 1974). Furthermore, the serotonin precursors, tryptophan and 5-hydroxytryptophan, fail to increase pain thresholds (Harvey \& Lints, 1971; Hole \& Marsden, 1975). Finally, microiontophoresis studies revealed that morphine's analgesic effects fail to correlate with its effects upon serotonergic cell body and projection systems (Haigler, 1978).

The human appetite suppressant, fenfluramine (FEN), produces short-term increases in rodent brain serotonin levels, followed by chronic long-term depletion (Clineschmidt, Zacchei, Totaro, Pfleuger, McGuffin, \& Wishousky, 1978; Harvey \& McMaster, 1975) and produces irreversible morphological abnormalities in rodent median raphe serotonergic cells (Harvey \& McMaster, 
1975, 1977; Harvey, McMaster, \& Fuller, 1977). Therefore, if nociceptive sensitivity is altered by changes in serotonin levels, then FEN administration should produce short-term analgesia followed by hyperalgesia 48-72 $\mathrm{h}$ thereafter. Thus, Experiment 1 determined FEN effects upon rodent pain thresholds, including reactivity to electric shock (the flinch-jump test), radiant heat (the tail-flick, TF, test), and operant psychophysical thresholds (the liminal escape, LE; test). The last procedure has been shown to reflect both an organism's evaluation of the relative aversiveness of a given stimulus and its motivation to respond, or not, to terminate the stimulus (Bodnar, Kelly, Brutus, Mansour, \& Glusman, 1978). In addition, the intertrial interval behavior generated by this procedure reliably indicates alterations in the organism's ability to respond and thereby serves to quantify the relative influence of nonspecific factors in the analgesic response. Experiment 2 examined whether FEN treatment produces morphological abnormalities in brain tissue.

\section{EXPERIMENT 1}

\section{Method}

Seventy-three male albino Sprague-Dawley rats were hou sed singly and were maintained on an ad-lib diet of rat chow and water. Animals were placed on a 12-h light/12-h dark cycle and were tested 1-7 h into the light cycle. Flinch-jump thresholds were determined in a modification of Evans' (1961) procedure and are described in detail elsewhere (Bodnar et al., 1978). TF latencies (D'Amour \& Smith, 1941) were determined using a radiant heat source (IITC analgesia meter) mounted $8 \mathrm{~cm}$ above the tail of a restrained animal. The thermal stimulus was applied to the dorsum of the tail $4 \mathrm{~cm}$ proximal to the tip, and its intensity was adjusted to produce a baseline TF latency of 3-4 sec. Three trials, separated at 30-sec intervals, were run daily.

The contingency of the LE test, described in detail elsewhere (Bodnar et al., 1978), was such that footshock was delivered for $10 \mathrm{sec}$ unless the rat pressed a lever three times to initiate a $20-\mathrm{sec}$ intertrial interval. One hundred trials were distributed evenly over a session and across intensities $(.2, .4, .6, .8,1.0 \mathrm{~mA})$ that were tested in blocks of four trials in counterbalanced fashion. The probability and latency to escape were recorded separately at each intensity for the last 80 trials of the session. Intertrial behavior was determined by the amount of time (in seconds) that contact was made with the lever during the intertrial in terval.

Four days of baseline determinations were completed for each test. Flinch-jump thresholds were then determined $.5 \mathrm{~h}$ and $72 \mathrm{~h}$ following respective intraperitoneal injections of FEN at doses of $0,2.66,6.65,13.3$, and $26.6 \mathrm{mg} / \mathrm{kg}(1 \mathrm{ml}$ normal saline $/ \mathrm{kg}$ body weight) in five matched groups of six animals each. Twenty other animals, divided into five matched groups of four rats each, received FEN at the five stated doses, with TF latencies determined $.5,24,48,72$, and $96 \mathrm{~h}$ following the injections. To avoid tissue damage in testing TF latencies, the trials were automatically terminated if a withdrawal response to the heat stimulus did not occur within $6 \mathrm{sec}$. Finally, 23 rats matched for LE thresholds received either FEN at a dose of $26.6 \mathrm{mg} / \mathrm{kg}(\mathrm{n}=14)$ or a vehicle (saline) $(\mathrm{n}=9)$, with thresholds determined $.5,24,48$, and $72 \mathrm{~h}$ later.

\section{Results}

Flinch-jump test. Figure 1 shows that while jump

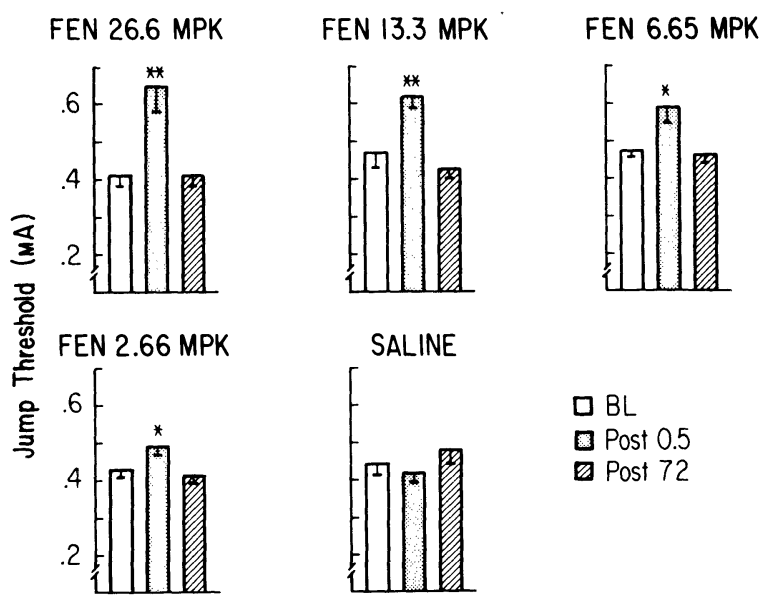

Figure 1. Mean alterations in jump thresholds (+SEM) 5 and $72 \mathrm{~h}$ following acute exposure to either fenfluramine (FEN) at doses of $26.6,13.3,6.65$, and $2.66 \mathrm{mg} / \mathrm{kg}$ or saline. There were six animals in each group.

thresholds were increased in a dose-dependent manner $.5 \mathrm{~h}$ following FEN, they failed to decrease below control values $72 \mathrm{~h}$ thereafter. Significant differences were observed over time $[F(2,50)=20.69, \mathrm{p}<.001]$ for the interaction between groups and time $[\mathrm{F}(8,50)=4.53$, $\mathrm{p}<.01]$, but not among groups $[\mathrm{F}(4,25)=1.12]$. FEN significantly increased jump thresholds $.5 \mathrm{~h}$ following administration at all doses tested: $26.6[\mathrm{t}(10)=3.09$, $\mathrm{p}<.05], 13.3(\mathrm{t}=6.19, \mathrm{p}<.01), 6.65(\mathrm{t}=2.85, \mathrm{p}<.05)$, $2.66 \mathrm{mg} / \mathrm{kg}(\mathrm{t}=3.20, \mathrm{p}<.05)$. By contrast, neither vehicle treatment $.5 \mathrm{~h}$ prior to testing $(\mathrm{t}=.72)$ nor any FEN dose $72 \mathrm{~h}$ following treatment significantly altered jump thresholds.

TF test. Figure 2 shows that while latencies were increased in a dose-dependent manner $.5 \mathrm{~h}$ following the injection, they failed to decrease below control levels $72 \mathrm{~h}$ thereafter, except for the lowest FEN dose. Significant differences were observed over time $[F(5,75)=15.56$, $\mathrm{p}<.01]$ for the interaction between groups and time $[F(20,75)=2.48, p<.01]$, but not among groups $[F(4,15)=.97]$. FEN significantly elevated latencies $.5 \mathrm{~h}$ after injection at doses of $26.6[\mathrm{t}(6)=5.38, \mathrm{p}<.01]$ and $13.3 \mathrm{mg} / \mathrm{kg}(\mathrm{t}=8.88, \mathrm{p}<.01)$, but it failed to alter latencies following the 6.65- $(\mathrm{t}=.88), 2.66-(\mathrm{t}=1.15)$, and $0-\mathrm{mg} / \mathrm{kg}(\mathrm{t}=.18)$ doses. Moreover, FEN failed to alter latencies $24,48,72$, and $96 \mathrm{~h}$ following the injection, except for a significant decrease induced by the lowest dose after $96 \mathrm{~h}(\mathrm{t}=5.79, \mathrm{p}<.01)$.

LE test. Figure 3 illustrates the time-dependent alterations in LE thresholds following FEN injection. Significant differences in time spent in shock were observed between $F E N$ - and saline-treated groups $[\mathrm{F}(1,21)=4.33$, $\mathrm{p}<.05]$ across time $[\mathrm{F}(4,84)=32.13, \mathrm{p}<.001]$ and across intensities $[F(4,84)=199.51, p<.001]$. Significant interactions were observed among all combinations of variables. Alterations in escape probability yielded an identical pattern. FEN-treated rats exhibited significant 


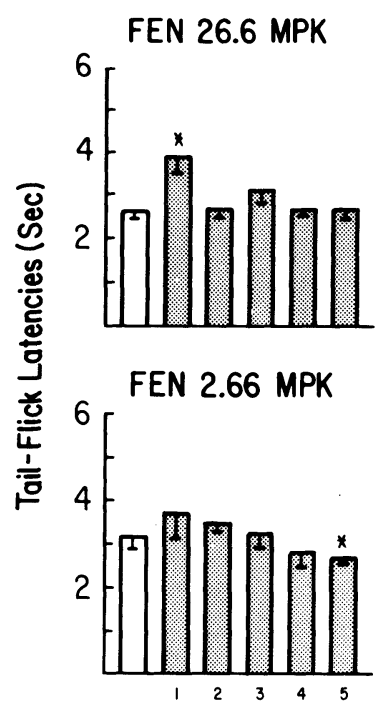

FEN 13.3 MPK

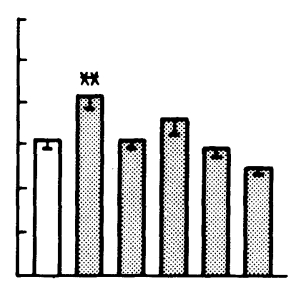

SALINE

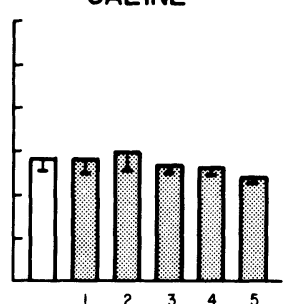

FEN 6.65 MPK

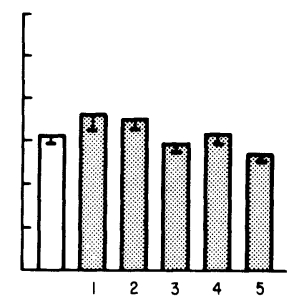

$\mathrm{BL}$ POST (h)

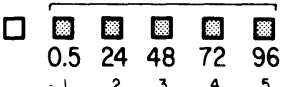

Figure 2. Mean alterations in tail-flick latencies (+SEM) $.5,24,48,72$, and $96 \mathrm{~h}$ following acu te exposure to either fenfluramine (FEN) at doses of $26.6,13.3,6.65$, and $2.66 \mathrm{mg} / \mathrm{kg}$ or saline. There were four animals in each group.

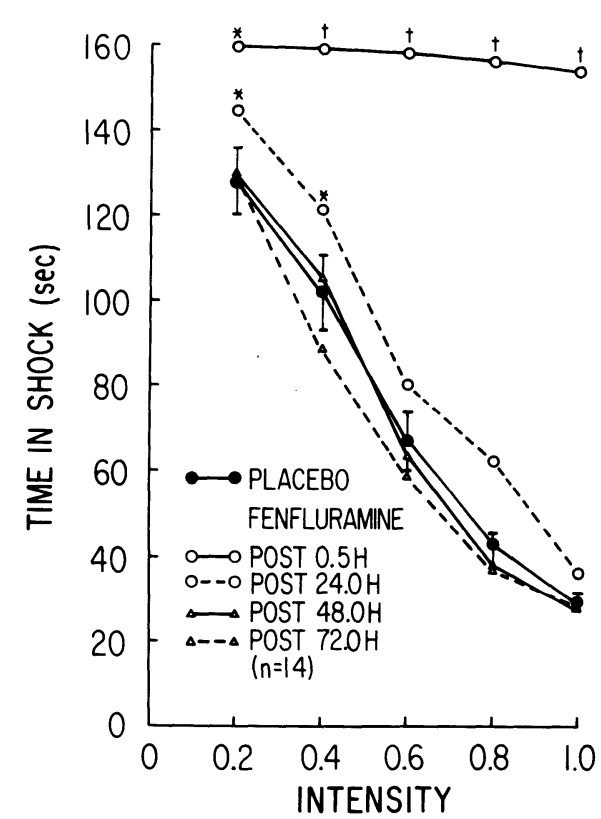

Figure 3. Time course of mean alterations in liminal escape thresholds across shock intensities for 14 rats treated with a $26.6-\mathrm{mg} / \mathrm{kg}$ dose of fenfluramine. The SEM of the placebo baseline for each intensity is displayed.

increases across the entire LE function $.5 \mathrm{~h}$ after injection, with the majority of animals failing to emit any appropriate escape or intertrial behaviors. On the other hand, saline-treated rats exhibited normal escape functions. Both LE thresholds and intertrial behaviors returned to within normal limits thereafter, except for significant increases at low shock intensities $24 \mathrm{~h}$ after injection.

\section{EXPERIMENT 2}

\section{Method}

Randomly selected rats that received either the $0-(n=3)$ or the $26.6-\mathrm{mg} / \mathrm{kg}$ FEN dose $(n=6)$ were anesthetized with sodium pentobarbital and were perfused trancardially with $.9 \%$ normal saline and $10 \%$ formalin. The brains were quickly rem oved, blocked, fixed for 7 days, embedded in paraffin, and sliced in 5 -micron coronal serial sections. Five of every 15 sections from the diencephalon to the caudal medulla were mounted and stained with cresyl violet. Light-microscopic examination of the tissue for morphological abnormalities was done by an experienced anatomist who had no knowledge of the behavioral results or treatment.

\section{Results}

No consistent degeneration of cells was observed in the medullary, pontine, and midbrain raphe nuclei, the locus coeruleus, the oculomotor (IIIrd) and trigeminal (Vth) cranial nerves, the substantia nigra, or the periaqueductal gray and the pontine reticular formation in FENtreated rats. Except for occasional (one to two cells per section over three to four sections) clumping of glia around several neurons in the median raphe nucleus of two FEN-treated rats, no abnormalities were noted. These data are in accord with other recent reports that failed to find systematic abnormalities (Funderburk, 1977; Gibbons, Glusman, Barr, Bridger, \& Leibowitz, 1978).

\section{DISCUSSION}

The hypotheses that pain thresholds would increase soon after FEN injection and subsequently decrease were partially confirmed. FEN increased nociceptive thresholds on all three pain tests in a dose-dependent manner $5 \mathrm{~h}$ following injection, a time when FEN increases brain serotonin levels (Clineschmidt et al., 1978). Differences in effective analgesic FEN doses were observed 
for the flinch-jump thresholds $(2.66 \mathrm{mg} / \mathrm{kg})$, TF latencies $(13.3 \mathrm{mg} / \mathrm{kg})$, and $\mathrm{LE}$ thresholds $(26.6 \mathrm{mg} / \mathrm{kg}) .5 \mathrm{~h}$ following injection, with the last effect attributable to disruption of overt behaviors as confirmed by elimination of ongoing intertrial behaviors that reliably indicate changes in motor performance (Dinsmoor, Matsuoka, \& Winograd, 1958; Davis \& Burton, 1974) but not analgesic performance (Bodnar et al., 1978). FEN failed to alter intertrial behaviors following the lower doses, indicating that the observed antinociceptive responses were not due to nonspecific factors at these levels.

The present study also demonstrated that FEN failed to lower basal flinch-jump, TF, and LE thresholds 48-72 $\mathrm{h}$ after injection (except for a small but significant decrease in TF latencies $96 \mathrm{~h}$ following the lowest FEN dose), despite its effects of long-term serotonin depletions (Clineschmidt et al., 1978). These data agree with the failure of serotonin content depletion to decrease basal pain thresholds observed in some (Blasig et al., 1973; Harvey et al., 1974; Hole \& Lorens, 1975), but not all (Tenen, 1967; see review by Messing \& Lytle, 1977), studies. One explanation for these discrepancies includes the possibility that serotonin must be reduced to some minimal critical level at specific loci to induce hyperalgesia. Alternatively, procedures (such as those that produce diencephalic and telencephalic lesions) that concomitantly lowered pain thresholds and brain serotonin (Harvey \& Lints, 1971; Lints \& Harvey, 1969; Lorens et al., 1970; Yunger \& Harvey, 1973) also interrupted other neurotransmitter and neuropeptide pathways. It is concluded that FEN increases pain thresholds in a test-specific fashion, but whether this analgesia is due to release of serotonin is open to further study.

\section{REFERENCES}

Basbaum, A. I., Marley, N. J. E., O'Keefe, J., \& Clanton, C. H. Reversal of morphine and stimulus-produced analgesia by subtotal spinal cord lesions. Pain, 1977, 3, 43-56.

Blasig, J., Reinhold, K., \& Herz, A. Effect of 6-hydroxydopamine, 5-hydroxytryptamine, 5,6-dihydroxytryptamine and raphe lesions on the antinociceptive actions of morphine in rats. Psychopharmacologia, 1973, 31, 111-119.

Bodnar, R. J., Kelly, D. D., Brutus, M., Mansour, A., \& Glusman, M. 2-deoxy-D-glucose-induced decrements in operant and reflex pain thresholds. Pharmacology, Biochemistry and Behavior, 1978, 9, 543-549.

Clineschmidt, B. V., Zacchei, A. G., Totaro, J. A., Pfleuger, A. B., McGuffin, J. C., \& Wishousky, T. I. Fenfluramine and brain serotonin. Annals of the New York Academy of Science, 1978, 305, 222-241.

D'Amour, F. E., \& Smith, D. L. A method for determining loss of pain sensation. Journal of Pharmacology and Experimental Therapeutics, 1941, 72, 74-79.

Davis, H., \& Burton, J. The measurement of response force during a leverpress shock-escape procedure in rats. Journal of the Experimental Analysis of Behavior, 1974, 22, 433-440.

Dinsmoor, J. A., Matsuoka, Y., \& Winograd, E. Bar-holding and preparatory response in escape-from-shock training. Journal of Comparative and Physiological Psychology, 1958, 51, 627-639.

Evans, W. O. A new technique for the investigation of some analgesic drugs on a reflexive behavior in the rat. Psychopharmacology, 1961, 2, 318-325.

FUnDerbuRK, W. H. Lack of cytotoxic effect of fenfluramine. Neurochemical Research, 1977, 2, 723-724.

Gibbons, J. L., Glusman, M., Barr, G. A., Bridger, W. H., \& Leıвowitz, S. F. Serotonergic mechanisms in aggression. Neuroscience Abstracts, 1978, 4, 493.

Gorlitz, B. D., \& Frey, J. J. Central monoamines and antinociceptive drug action. European Journal of Pharmacology, 1972, 20, 171-180.

HAIGLER, H. J. Morphine: Effects of serotonergic neurons and neurons in areas with a serotonergic input. European Journal of Pharmacology, 1978, 51, 361-376.

HaRvey, J. A., \& Lints, C. E. Lesions in the medial forebrain bundle: Relationship between pain sensitivity and telencephalic content of serotonin. Journal of Comparative and Physiological Psychology, 1971, 74, 28-36.

Harvey, J. A., \& McMaster, S. E. Fenfluramine: Evidence for a neurotoxic action on midbrain and a long-term depletion of serotonin. Communications in Psychopharmacology, 1975, 1, 217-228.

Harvey, J. A., \& McMaster, S. E. Fenfluramine: Cumulative neurotoxicity after chronic treatment with low dosages in the rat. Psychopharmacological Communications, 1977, 1, 3-17.

Harvey, J. A., McMaster, S. E., \& Fuller, R. W. Comparison between the neurotoxic and serotonin-depleting effects of various halogenated derivatives of amphetamine in the rat. Journal of Pharmacology and Experimental Therapeutics, 1977, 202, 581-589.

Harvey, J. A., Schlosberg, A. J., \& Yunger, L. M. Effects of p-chlorophenylalanine and brain lesions on pain sensitivity and morphine analgesia in the rat. Advances in Biochemical Psychopharmacology, 1974, 10, 233-245.

Hole, K., \& Lorens, S. A. Response to electric shock in the rat: Effects of selective midbrain raphe lesions. Pharmacology, Biochemistry and Behavior, 1975, 3, 95-102.

Hole, K., \& Marsden, C. A. Unchanged sensitivity to electric shock in L-tryptophan treated rats. Pharmacology, Biochemistry and Behavior, 1975, 3, 307-309.

Lints, C. E., \& Harvey, J. A. Altered sensitivity to foot shock and decreased brain content of serotonin following brain lesions in the rat. Journal of Comparative and Physiological Psychology, 1969, 67, 23-31.

Lorens, S. A., Sorenson, J. P., \& Harvey, J. A. Lesions in the nuclei accumbens septi of the rat: Behavioral and neurochemical effects. Journal of Comparative and Physiological Psychology, 1970, 75, 284-290.

Lytle, L. D., Messing, R. B., Fisher, L., \& Phebus, L. Effects of chronic corn consumption on brain serotonin and the response to electric shock. Science, 1975, 190, 692-694.

Messing, R. B., Fisher, L. A., Phebus, L., \& Lytle, L. D. Interaction of diet and drug in the regulation of brain 5hydroxyindoles and the response to painful electric shock. Life Sciences, 1976, 18, 707-714.

Messing, R. B., \& LytLe, L. D. Serotonin-containing neurons: Their possible role in pain and analgesia. Pain, 1977, 4, 2-21.

Proudfit, H. K., \& Anderson, E. G. Morphine analgesia: Blockade by raphe magnus lesions. Brain Research, 1975, 98, 612-618.

Samanin, R., Bernasconi, S., \& Quattrone, A. Antinociceptive action of quipazine: Relation to central serotonergic receptor stimulation. Psychopharmacologia, 1976, 46, 219-222.

Samanin, R., Ghezzi, D., Mauron, C., \& Valzelli, L. Effect of midbrain raphe lesions on the antinociceptive action of morphine and other analgesics in rats. Psychopharmacology, 1973, 33, 365-368.

TEnen, S. S. The effects of p-chlorophenylalanine, a serotonin depletor, on avoidance acquisition, pain sensitivity and related behavior in the rat. Psychopharmacologia, 1967, 10, 204-219.

TEnen, S. S. Antagonism of the analgesic effect of morphine and other drugs by p-chlorophenylalanine, a serotonin depletor. Psychopharmacology, 1968, 12, 278-285.

VoGT, M. The effect of lowering the 5-hydroxytryptamine content of the rat spinal cord on analgesia produced by morphine. Journal of Physiology (London), 1974, 236, 483-498.

YUNGeR, L. M., \& HARVEY, J. A. Effect of lesions in the medial forebrain bundle on three measures of pain sensitivity and noiseelicited startle. Journal of Comparative and Physiological Psychology, 1973, 83, 173-183.

(Received for publication March 27, 1982.) 